Thorax (1970), 25, 116.

\title{
Management of critical valvular outflow obstruction in neonates
}

\author{
R. H. B U R NELL, P. E. GHA D I A L I, M C. J OSEPH, \\ M. P A NET H \\ Departments of Paediatrics and Surgery, Brompton Hospital, London, S.W.3
}

\begin{abstract}
Severe pulmonary or aortic valve stenosis may be lethal to the neonate if untreated. Two patients suffering from pulmonary stenosis and four with aortic stenosis were relieved surgically with the use of full cardiopulmonary bypass. Both neonates with pulmonary stenosis did well, making them the youngest recorded survivors of such treatment. Two of the four patients with aortic stenosis have done well, the other two having severe endocardial fibro-elastosis. The indications and technique for cardiopulmonary bypass in this age group are briefly described.
\end{abstract}

The potentially lethal nature of severe pulmonary or aortic valve stenosis in infancy has often been stressed in the past - for example, by Mustard, Jain, and Trusler (1968) and Hastreiter, Oshima, Miller, Lev, and Paul (1963). Not so well agreed is the surgical management. Operation in older children is usually conducted on cardiopulmonary bypass, but, to quote one textbook, 'The chief disadvantage of this procedure is the necessity of submitting the patient to extra-corporeal circulation; but this is no longer considered a serious handicap, except, perhaps, in very young critically ill infants' (Gasul, Arcilla, and Lev, 1966). We have recently operated on six neonates with critical outflow obstruction, and we consider the advantages of cardiopulmonary bypass outweigh any theoretical disadvantages, even at this age.

\section{MATERIAL AND METHODS}

The clinical presentation and investigations are detailed in the Table. There were two neonates with severe pulmonary valve stenosis, right-to-left shunting across a patent foramen ovale, and marked arterial desaturation. The other four neonates were in congestive heart failure with severe aortic valve stenosis, one having an additional patent foramen ovale with left-to-right shunting. Standard cardiac catheterization procedures were performed before operation in all cases, supplemented by selective biplane angiography in the two cases of pulmonary stenosis.

Operations were performed within 24 hours of cardiac catheterization. In each case total body perfusion was accomplished through a vertical median sternotomy with insertion of a thin-walled metal cannula into the ascending aorta through a small stab incision. Excellent venous drainage was obtained b५ a single catheter inserted through the right atria appendage. (The alternative technique of individuat caval cannulation is potentially dangerous in these small patients, since kinking and occlusion of the cavo readily occur, resulting in rapid and dangerous rise in venous pressure. In addition venous pressule monitoring is technically difficult.) Decompression of the left heart was also obtained by this technique if those cases with a patent foramen ovale; in the remaining cases a left ventricular vent was used Elective fibrillation was used for the pulmonat valvotomies, which were performed through a trans: verse arteriotomy. During this procedure the tempera ture was gradually reduced to permit elective circula tory arrest for closure of the foramen ovale. The neonates were rewarmed by restarting the circulatio and defibrillation was not necessary. Operative pre? sure recordings in both cases confirmed the cathetef finding of right ventricular systolic pressures in exces of systemic pressure. After valvotomy the right veb tricular systolic pressures were $26 \mathrm{~mm} . \mathrm{Hg}$ and 49 $\mathrm{mm}$. $\mathrm{Hg}$ respectively, compared with systemic prez sures of $85-90 \mathrm{~mm}$. Hg.

A similar procedure was followed for aortic valvos tomy in case 3, who had in addition a patent foramen ovale with left-to-right shunt. Cases 4,5 , and 6 has only an open aortic valvotomy, and for this the bodf temperature was not reduced, since the brief periof of coronary ischaemia is well tolerated unless there is associated fibro-elastosis.

\section{RESULTS}

Case 3 died 10 hours after operation. His course after admission was uniformly downhill, and post-operatively increasing doses of isoprenaling were needed to maintain circulation. Necrop 
T A B L E

CLINICAL AND INVESTIGATIONAL DATA

\begin{tabular}{|c|c|c|c|c|c|c|c|c|c|c|c|c|c|c|c|c|}
\hline U. & 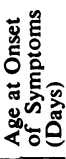 & 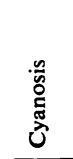 & 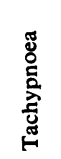 & 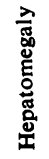 & $\begin{array}{l}\text { हूँّ } \\
\text { हूँ } \\
\text { ठू }\end{array}$ & 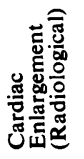 & نُ نِّن & 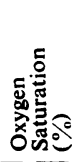 & 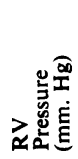 & 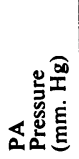 & 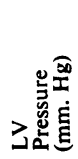 & 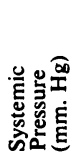 & 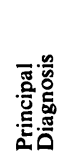 & ठั & 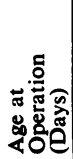 & 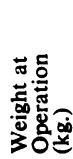 \\
\hline 1 & 3 & ++ & + & + & 0 & + & RVH & 40 & $102 / 5$ & - & $76 / 5$ & $78 / 50$ & $\mathrm{PS}$ & $\begin{array}{c}\text { PFO } \\
\left(\begin{array}{l}\mathrm{R} \rightarrow \mathrm{L}) \\
\text { shunt }\end{array}\right.\end{array}$ & 5 & $3 \cdot 2$ \\
\hline 2 & 1 & +++ & + & 0 & 0 & ++ & RVH & 20 & $113 / 8$ & - & $60 / 3$ & - & PS & $\begin{array}{c}\text { PFO } \\
(\mathrm{R}-\mathrm{L}) \\
\text { shunt }\end{array}$ & 4 & 3.0 \\
\hline 3 & 2 & 0 & ++ & + & 0 & ++ & $\begin{array}{l}\text { LVH } \\
\text { RVH }\end{array}$ & 97 & $84 / 8$ & $84 / 44$ & $115 / 14$ & $73 / 60$ & AS & $\begin{array}{c}\text { PFO } \\
(\mathbf{L F} \rightarrow \mathbf{R}) \\
\text { shunt }\end{array}$ & 3 & $2 \cdot 7$ \\
\hline 4 & 7 & 0 & ++ & ++ & ++ & +++ & $\begin{array}{c}\text { LVH } \\
\text { with, } \\
\text { 'strain, }\end{array}$ & 96 & $55 / 8$ & $48 / 36$ & $150 / 20$ & $55 / 44$ & AS & - & 10 & 3.9 \\
\hline 5 & 6 & + & ++ & + & 0 & ++ & $\begin{array}{l}\text { LVH } \\
\text { with, }\end{array}$ & 86 & $40 / 2$ & $40 / 20$ & $87 / 6$ & $43 / 35$ & AS & - & 12 & 3.7 \\
\hline 6 & 14 & 0 & ++ & 0 & 0 & ++ & $\begin{array}{l}\text { LVH } \\
\text { with, } \\
\text { 'strain' }\end{array}$ & 95 & $38 / 2$ & $14 / 7$ & $130 / 10$ & $52 / 40$ & AS & $\underset{\text { (mild) }}{\mathrm{PS}}$ & 22 & 3.4 \\
\hline
\end{tabular}

Cyanosis, tachypnoea, hepatomegaly, oedema and cardiac enlargement all graded $0 \rightarrow+++$

$\mathbf{R V H}=$ right ventricular hypertrophy; $\mathbf{L V H}=$ left ventricular hypertrophy; $\mathrm{PS}=$ val vular pulmonic stenosis; $A S=$ valvular aortic stenosis; PFO = patent foramen ovale.

confirmed that an adequate aortic valvotomy and closure of the patent foramen ovale had been achieved, but severe endocardial fibro-elastosis was present in the left ventricle. Case 5 died abruptly within one hour following operation, having appeared to have done well initially. Necropsy confirmed an adequate aortic valvotomy, but marked endocardial fibro-elastosis was present in the left ventricle.

The remaining four patients are all alive and asymptomatic. Case 4 is now 8 months old and has developed normally. He has an aortic ejection systolic murmur but no evidence of aortic regurgitation. A chest radiograph shows a normal-sized heart, but the electrocardiogram shows persistence of left ventricular hypertrophy. Case 6 is now 7 months old. He is normally grown and asymptomatic. Like Case 4 his intellectual progress is normal. On auscultation there is an aortic ejection systolic murmur but no diastolic murmur. Chest radiographs show considerable diminution in cardiomegaly, but the electrocardiogram also shows persistence of left ventricular hypertrophy.

The two patients with pulmonary stenosis and shunt reversal across a patent foramen ovale have done well. At 3 months of age both were progressing normally without evidence of cyanosis or heart failure.

\section{DISCUSSION}

PULMONARY VALVE STENosis It is generally agreed that at any age pulmonary valvotomy is best performed under direct vision, though some surgeons still except the critically ill neonate. In infancy the usual technique consists of inflow stasis by caval occlusion with or without hypothermia, and good results have been reported (Cooley and Hallman, 1966 ; Mustard et al., 1968). We preferred to use cardiopulmonary bypass in infants for several reasons. First, it affords the surgeon more time adequately to open what is often a small dysplastic valve, with less danger of producing pulmonary regurgitation, as occurred in 11 of Mustard's 26 cases. Although pulmonary insufficiency is probably benign in most cases if the pulmonary artery pressure is not elevated (Burnell, Woodson, Lees, and Starr, 1969), it is best avoided. Secondly, extracorporeal circulation allows closure of the foramen ovale at the same operation, preventing right to left shunting, which often persists after adequate pulmonary valvotomy, due to non-compliance of the right ventricle, and possibly necessitating a second operation (Mustard et al., 1968). If this shunting is not great, as more often occurs in older patients, then the benefit is probably marginal. However, when it is pronounced, as may occur in very young patients, systemic and myocardial oxygenation in the post-operative phase may be grossly deficient, particularly if pulmonary complications occur following surgery in the infant. It was felt that these reasons were equally applicable in neonates when case 1 was seen. A third advantage became obvious as soon as bypass was established. This infant was severely anoxic and acidotic and 
her heart was dilated and tense. Within moments of improved myocardial oxygenation the heart diminished in size and became much less tense. Similar findings were noted in case 2 . It is our belief that the complete relief of hypoxia and acidosis possible with this technique contributed to the uneventful post-operative course in both patients. This contrasts with inflow occlusion, which temporarily must increase hypoxia and acidosis in an already depressed myocardium. Gersony, Bernhard, Nadas, and Gross (1967) pursued similar reasoning in advocating hyperbaric surgery for these infants, but this technique is not as widely available as cardiopulmonary bypass.

These two babies appear to be the youngest reported patients with severe pulmonary stenosis successfully corrected under cardiopulmonary bypass.

AORTIC VALVE STENOSIS The infant with severe aortic valve stenosis has a grim prognosis and justifies early operation, despite the frequency of associated lesions, in particular endocardial fibroelastosis. Hastreiter et al. (1963), in an excellent review, consider that many such cases are intermediate forms between the hypoplastic left heart syndrome and isolated aortic valvular stenosis of older children, and considerable detail is given in their article of the various associated anomalies. While we realize that some of these anomalies can be defined by selective angiography, we have deliberately avoided this procedure because of the risk inherent in any patient with severe left ventricular outflow obstruction (two deaths in 15 patients of Hastreiter $e t$ al. being attributed to left ventricular angiography). Instead, we prefer the surgeon to diagnose and deal with anomalies present, recognizing that this will inevitably lead to increased difficulty in some patients. To follow this procedure the surgeon will require more time than that afforded by inflow occlusion, as for example described by Cooley and Hallman (1966), and we therefore advocate the use of cardiopulmonary bypass even in the neonate. Correcting the valve anomaly alone may require more than the two or three minutes afforded by inflow occlusion with normothermia if lethal aortic regurgitation is to be avoided.

Various reports of surgery in congenital aortic stenosis (Lees, Hauck, Starkey, Nadas, and Gross, 1962 ; Ellis, Ongley, and Kirklin, 1962) do not contain any neonates. Cooley and Hallman (1966) do not consider the neonates separately in their series of 20 infants, but mention that 'cardiopulmonary bypass was utilised in all but a few newborn infants in whom a modified form of caval occlusion was employed for open valvo tomy'. Hastreiter et al. (1963) reported twक neonates who survived aortic valvotomy op bypass.

Similarly, several large series of operations wition extracorporeal circulation in infants have beeb reported (Sloan, Mackenzie, Morris, Stern, and Sigmann, 1962 ; Baffes, Riker, and DeBoer, 1964) but there do not appear to be more than one of two neonates with aortic valve stenosis who surx vived. Therefore our cases 4 and 6 join a selects group. It is admitted that the encouraging results are partly due to favourable anatomy (i.e., $\overrightarrow{\mathrm{a}}$ relatively well-formed aortic valve), in contrast $t 8$ cases 3 and 5 , in whom severe left ventriculap endocardial fibro-elastosis was present and theृ aortic valves consisted of irregular masses of myxomatous material. Our point in reporting these patients is to emphasize that surgery wit cardiopulmonary bypass is feasible, and, we believe, essential if a better salvage rate is to bo achieved in this group of neonates.

\section{PERFUSION TECHNIQUE}

The perfusion system had a total priming volume of $700 \mathrm{ml}$. and included an infant-size rotating dise oxygenator. A mean perfusion pressure of 50-60 $\mathrm{mm}$. $\mathrm{Hg}$ was maintained and this required a perfusiog rate of about $200 \mathrm{ml} . / \mathrm{min} . / \mathrm{kg}$. body weight. ff circulatory arrest was necessary the cooling and res warming rates were such as not to exceed a gradien of $5^{\circ} \mathrm{C}$. between the blood in the arterial limb of the oxygenator and the pharynx. The total circulatorg arrest periods varied between $7 \frac{1}{2}$ minutes at $30^{\circ} \mathrm{E}$. and 29 minutes at $12^{\circ} \mathrm{C}$.

We think the following points are important fo을 perfusions in neonates:

1. The circuit shall be primed with blood drawn into heparinized bags within three hours of operation

2. Bubble oxygenator systems are not used because. we believe that the presence of silicone and/or antio foam substances introduces additional hazards. $O$

3. Before starting the perfusion the blood warmed to $37^{\circ} \mathrm{C}$. by recirculation, to prevent excess sive heat loss to which neonates are particularly prone During this preliminary period the $\mathrm{PCO}_{2}$ is adjusted to between 35 and $40 \mathrm{~mm}$. $\mathrm{Hg}$.

4. This group of patients requires a much high flow rate than expected to maintain an adequate mean perfusion pressure.

Our thanks are due to Drs. S. Tucker, C. Oakle D. Gairdner, and A. Robinson for referring the case and to Dr. G. Miller, Director of the Cardiac Laborg tory, for help with the investigations. 


\section{REFERENCES}

Baffes, T. G., Riker, W. L., and DeBoer, A. (1964). Open-heart surgery for infants and small children, mortality and morbidity. Arch. Surg., 88, 675.

Burnell, R. H., Woodson, R. D., Lees, M. H., and Starr, A. (1969). Right ventricular performance in dogs following pulmonary valvectomy. Surgery, 65, 952.

Cooley, D. A., and Hallman, G. L. (1966). Surgical Treatment of Congenital Heart Diseases, p. 67. Lea and Febiger, Philadelphia.

Ellis, F. H., Ongley, P. A., and Kirklin, J. W. (1962). Results of surgical treatment for congenital aortic stenosis. Circulation, 25, 29.

Gasul, B. M., Arcilla, R. A., and Lev, M. (1966). Heart Disease in Children, p. 792. Lippincott, Philadelphia.
Gersony, W. M., Bernhard, W. F., Nadas, A. S., and Gross, R. E (1967). Diagnosis and surgical treatment of infants with critical pulmonary outflow obstruction. Circulation, 35, 765.

Hastreiter, A. R., Oshima, M., Miller, R. A., Lev, M., and Paul, M. H. (1963). Congenital aortic stenosis syndrome in infancy. Ibid., 28, 1084.

Lees, M. H., Hauck, A. J., Starkey, G. W. B., Nadas, A. S., and Gross, R. E. (1962). Congenital aortic stenosis. Operative indications and surgical results. Brit. Heart J., 24, 31

Mustard, W. T., Jain, S. C., and Trusler, G. A. (1968). Pulmonary stenosis in the first vear of life. Ibid., 30, 255.

Sloan, H., Mackenzie, J., Morris, J. D., Stern, A., and Sigmann, J. (1962). Open heart surgery in infancy. J. thorac. cardiovasc. Surg., 44, 459. 